\title{
Article \\ A Novel Dual-Band Implantable Antenna for Pancreas Telemetry Sensor Applications
}

\author{
Maria Matthaiou *(D), Stavros Koulouridis* $*$ and Stavros Kotsopoulos
}

\author{
Electrical and Computer Engineering Department, University of Patras, 26504 Patras, Greece; \\ kotsop@ece.upatras.gr \\ * Correspondence: ece8407@upnet.gr (M.M.); stavros.koulouridis@upatras.gr (S.K.)
}

\begin{abstract}
In this study, a novel implantable dual-band planar inverted F-antenna (PIFA) is proposed and designed for wireless biotelemetry. The developed antenna is intended to operate on the surface of the pancreas within the Medical Device Radiocommunications Service (MedRadio 401-406 MHz) and the industrial scientific and medical band (ISM, 2.4-2.5 GHz). The design analysis was carried out in two steps, initially inside a canonical model representing the pancreas, based on a finite element method (FEM) numerical solver. The proposed antenna was further simulated inside the human body taking into account the corresponding dimensions of the tissues and the electrical properties at the frequencies of interest using a finite-difference time-domain (FDTD) numerical solver. Resonance, radiation performance, electrical field attenuation, total radiated power, and specific absorption rate (SAR), which determines the safety of the patient and the maximum permissible input power and other electromagnetic parameters, are presented and evaluated.
\end{abstract}

Keywords: implantable antenna; PIFA; SAR; biotelemetry

check for updates

Citation: Matthaiou, M.; Koulouridis, S.; Kotsopoulos, S. A Novel Dual-Band Implantable Antenna for Pancreas Telemetry Sensor Applications. Telecom 2022, 3, 1-16. https://doi.org/10.3390/ telecom3010001

Academic Editor: Sotirios K. Goudos

Received: 21 November 2021

Accepted: 10 December 2021

Published: 1 January 2022

Publisher's Note: MDPI stays neutral with regard to jurisdictional claims in published maps and institutional affiliations.

Copyright: () 2022 by the authors. Licensee MDPI, Basel, Switzerland. This article is an open access article distributed under the terms and conditions of the Creative Commons Attribution (CC BY) license (https:// creativecommons.org/licenses/by/ $4.0 /)$.

\section{Introduction}

In recent years, significant research has been made in wireless body area networks and their applications in the field of telemedicine. Specifically, implantable medical devices are widely used for the transmission of vital data. Their development creates the prospects for a better life quality of patients, especially those who suffer from chronic diseases [1]. For example, continuous non-invasive glucose monitoring can help patients suffering from diabetes, a very common, life-threatening disease. To carry out such an application, the antenna must be carefully designed, given that it provides a communication link between the internal and the external sensor and that it is responsible for the radiation performance and the transmission of the electromagnetic waves. Such an application could be used in a sensor that will be informed about the glucose levels of the pancreas, then send the results to a sensor on the surface or outside the body, which will communicate with a doctor via the internet and regulate the levels of insulin to be taken by the patient.

An implantable device has many requirements and a single operating band may not meet some of them since it needs to transmit data and be autonomous at the same time. Consequently, it is highly demanded to have multiband operation for other functions such as wireless power transfer and/or wake-up/sleep modes. Research on the dual band function of implantable antennas has been reported for example in [2-4].

This study is an extended version of our work reported in [5], where we presented the design of a novel implantable dual-band antenna and its performance simulated inside a cuboid pancreas model with dielectric properties of the pancreas. In this work, the proposed antenna's function is further analyzed through simulations inside the pancreas of a male and a female human phantom, taking into account the impact of the human body on the signal propagation and the safety limits of the absorbed energy by surrounding tissues. 
The antenna resonates at MedRadio and ISM bands, aiming to serve different functions of the implantable device. In order be small-sized, a shorting pin was inserted, given that it plays a significant role in the miniaturization of the antenna [6-10]. Research also has been conducted regarding the use of U-shaped slots to achieve the multiband operation of the patch antenna [11-14].

Furthermore, we focused on a printed double-resonance slotted patch antenna, loaded with $\mathrm{u}$-shaped slots and a pin that were used to introduce and tune the double resonance. The frequencies sought were the Medical Device Radiocommunications Service (MedRadio) 401-406 MHz and Industrial, Scientific, and Medical 2.4-2.5 GHz frequency bands. The former could serve for information transmission to an external receiver, while the latter could serve for wireless charging. The use of a full metallic ground plane thus had a second role. It could serve as backing for a circuit or other metallic structures without affecting the antenna performance [4]. In addition, we sought a slot antenna because of its superior far-field radiation properties and its robustness against tissue variability, which is usual in such designs.

The antenna design process followed a two-step approach: the first step was to achieve resonance inside an equivalent simplified model with the dielectric properties of the pancreas. To design the antenna, each element was inserted depending on the impact of the antenna behavior, surface current density, and radiation performance. Some useful conclusions are presented in every stage of the design until resonance was achieved. In this step, we used HFSS Software (High Frequency Structure Simulator) [15].

The second step was to implant the antenna in a more accurate human phantom with the help of the software Sim4Life of ZMT, Zurich MedTech [16]. The behavior of the antenna was analyzed when it was placed on the surface of the pancreas of two anatomical models (male and female) with all the electric properties and geometrical characteristics of biological tissues for the analysis of signal behavior as it propagated through the human organs. Radiation performance, electric field distributions, SAR values, and maximum allowable power values as well as electric field fluctuations when the electromagnetic wave was away from the antenna were calculated and evaluated in each anatomical model, and a comparative study was performed between the two models.

\section{Methods and Results}

\subsection{Antenna Design}

The main objective of the proposed antenna design process was to be as small as possible, which made the design quite complex as it depended on many parameters (geometrical shape and size of the antenna components). To achieve a better size reduction, we chose a very thin substrate of high-dielectric material [8] and installed a small pin which transforms this antenna into a PIFA (planar inverted F-antenna). The choice of the pin position was based on the observation that the maximum size reduction would be achieved by placing the pin away from the zero point of the electric field as well as at a suitable point so that it did not affect the tuning of the antenna.

Furthermore, another requirement was to transmit in two frequency bands MedRadio and ISM for the transmission of vital data and its energy management. To achieve the function at both frequencies, two U-shaped slots were placed on the conductive surface which redefined the path of the surface currents. The basic geometry of the U-slotted antenna was first introduced in 1995 by Huyn and Lee [17].

The antenna was designed directly into the pancreas rectangle box displayed in Figure 1, and the shorting pin position and U-slots placement and dimensions were manually optimized to achieve optimum performance at the frequencies of interest, using HFSS Software (high frequency structure simulator) [15]. 


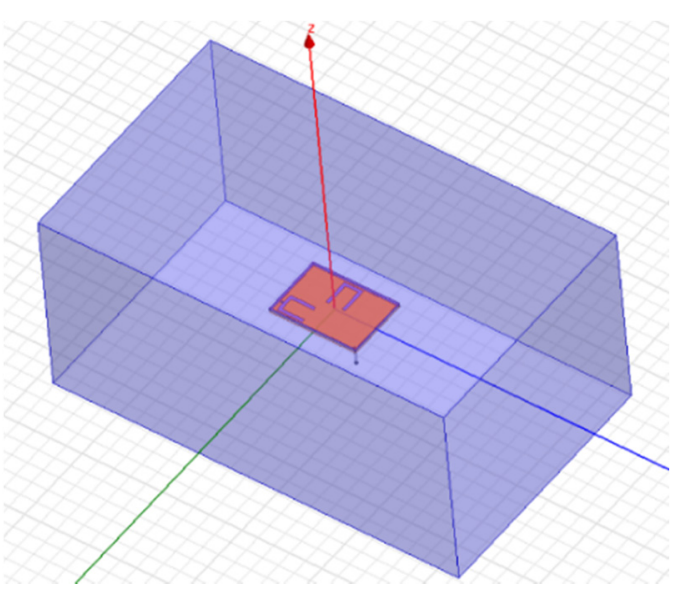

Figure 1. Proposed antenna design for pancreas implantation.

\section{Antenna Characteristics}

The patch surface and ground plane had dimensions of $18 \mathrm{~mm} \times 26 \mathrm{~mm}$ and $19 \mathrm{~mm} \times 27 \mathrm{~mm}$, illustrated in Figures 2 and 3. The substrate was made of high-dielectric material (Rogers RO $6010 \varepsilon \mathrm{r}=10.2$, $\tan \delta=0.023$ ) and a thickness of $0.635 \mathrm{~mm}$. An identical superstrate layer covered the patch surface to insulate the metallic radiating patch from the surrounding human tissues. In the edge of the antenna, we inserted a shorting pin with radius of $0.2 \mathrm{~mm}$, shown in Figure 2. Two U-shaped slots were added in the patch surface, with dimensions shown in Figure 1. A $50 \Omega$ coaxial cable of $5 \mathrm{~mm}$ length was used as feed, which consisted of an external conductor (radius $=0.48 \mathrm{~mm}$ ) made of dielectric material Teflon $(\mathrm{tm})(\varepsilon \mathrm{r}=2.2)$ and an internal one (radius $0.24 \mathrm{~mm})$.

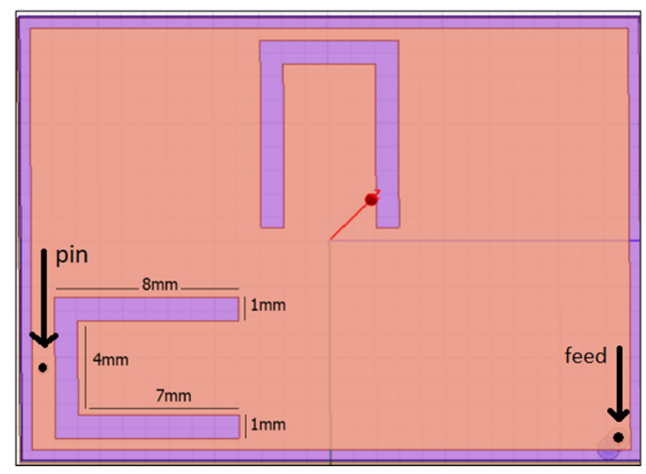

Figure 2. Proposed Antenna Characteristics.

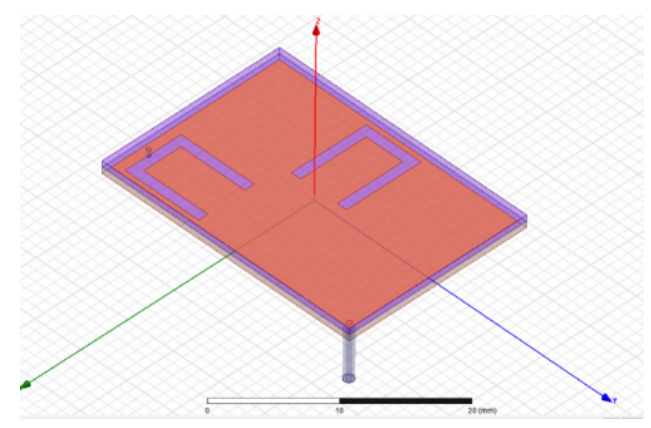

Figure 3. Design of the proposed antenna.

The antenna was designed in the center of a simplified equivalent model, with the electrical properties of the pancreas and the shape of a rectangle box of dimensions $74 \mathrm{~mm}$ 
$\times 127 \mathrm{~mm} \times 59 \mathrm{~mm}$. The electrical properties of the pancreas that represent the pancreas tissue at the frequencies of interest are shown in Table 1 from IT'IS database [18].

Table 1. Dielectric properties of the pancreas [18].

\begin{tabular}{ccc}
\hline Frequency & Relative Permittivity $(\varepsilon \mathbf{r})$ & Bulk Conductivity (S/m) \\
\hline $402.5 \mathrm{MHz}$ & 61.2155 & 0.8779 \\
$2.45 \mathrm{GHz}$ & 57.201 & 1.968 \\
\hline
\end{tabular}

\subsection{Radiation Performance Analysis}

\subsubsection{Resonance}

In order to understand the antenna behavior, resonance performance dependence on structure modifications was analyzed. For both frequencies, we requested that S11 resonance fell below $-10 \mathrm{~dB}$.

In the MedRadio band, before any structure modification, the antenna showed no resonance, as displayed in Figure 4. When the antenna turned into PIFA, we observed a resonance at $430 \mathrm{MHz}$. With every U-slot addition, the resonance improved, and the S11 reached $-20.7 \mathrm{~dB}$. The $10 \mathrm{~dB}$ bandwidth was $30.29 \mathrm{MHz}$.

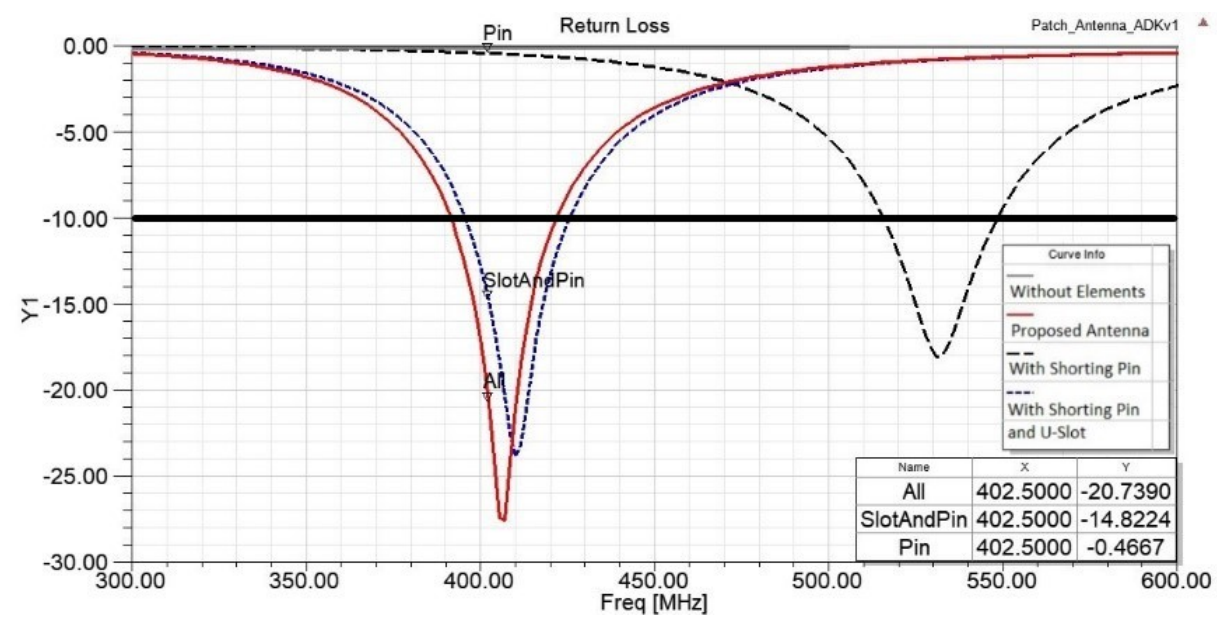

Figure 4. Reflection coefficient after antenna structure modifications in the MedRadio band in the pancreas model.

The impact on the reflection coefficient in the ISM band operation is shown in Figure 5. Without adding any elements, we observed a possible resonance although it did not cover the $-10 \mathrm{~dB}$ requirement. After the structure modifications, the existing resonance optimized and $\mathrm{S} 11$ was $-17.8 \mathrm{~dB}$ at the operating frequency of $2.45 \mathrm{GHz}$. The bandwidth was 225.2 MHz.

Overall, the proposed antenna performance on the desired operation frequencies satisfied the $-10 \mathrm{~dB}$ limit, indicated by the black line in Figures 4 and 5 . In addition, the $10 \mathrm{~dB}$ bandwidth covered the MedRadio and ISM bands. In addition, at $402.5 \mathrm{MHz}$ the real part of the impedance of the proposed antenna, extracted from our simulations, is $46.52 \Omega$ and the imaginary 8.19 , and at $2.45 \mathrm{GHz}$ the real part is $40.8 \Omega$ and the imaginary part is $7 \Omega$ as displayed in Figures 6 and 7.

\subsubsection{Surface Current Density}

The influence of the structure modifications on the antenna surface current density is presented. The impact of the antenna structure modifications on the current distribution is shown in Figures 8-11. 


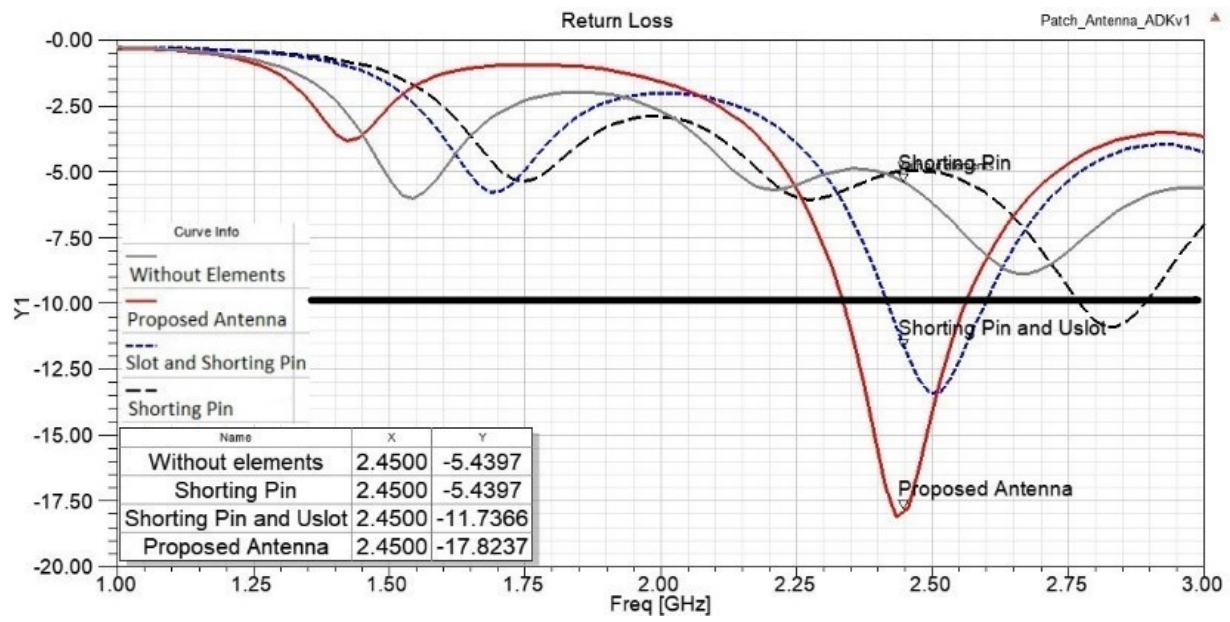

Figure 5. Reflection coefficient after antenna structure modifications in the ISM band in the pancreas model.

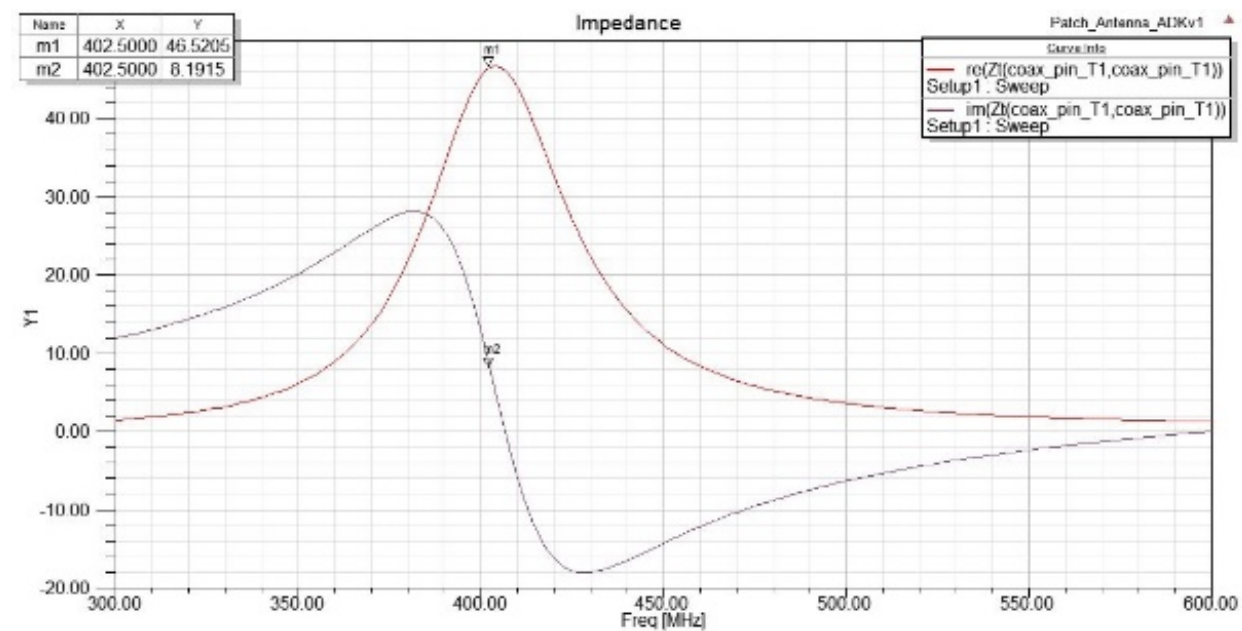

Figure 6. Calculated impedance of the antenna in the MedRadio band in the pancreas model.

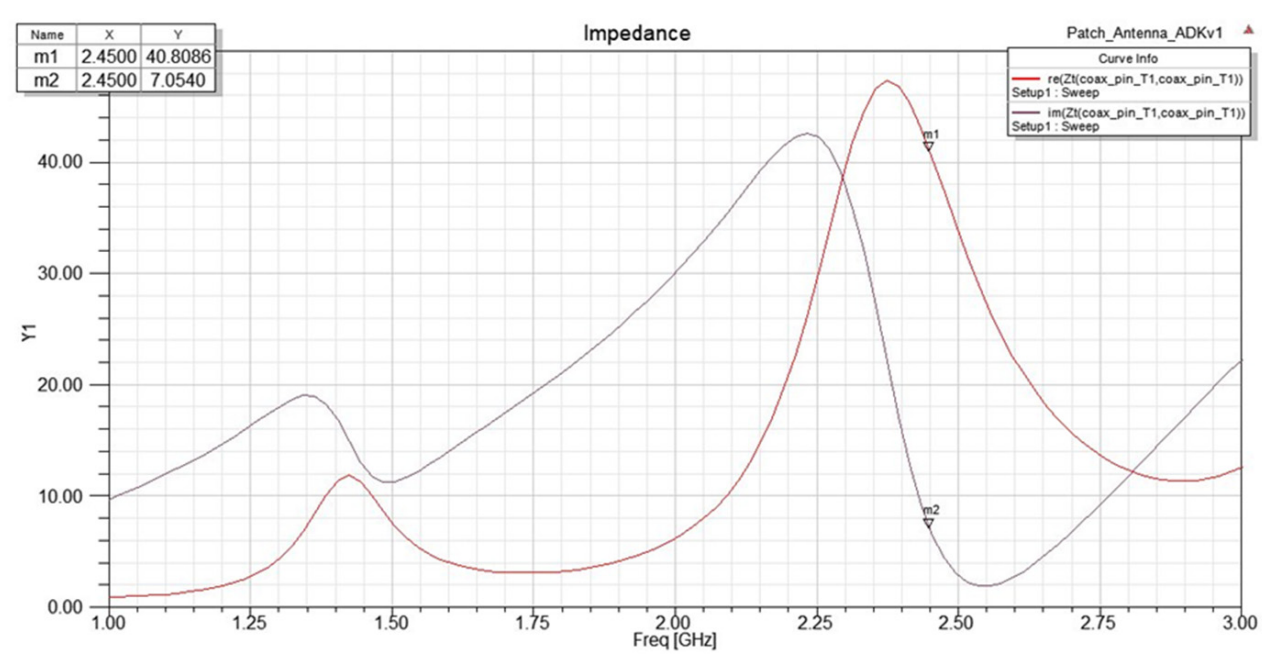

Figure 7. Calculated impedance of the antenna in the ISM band in the pancreas model. 


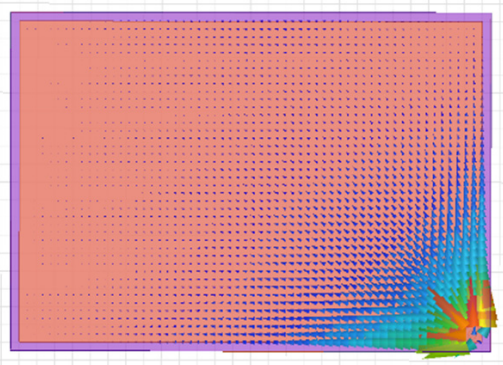

(a)

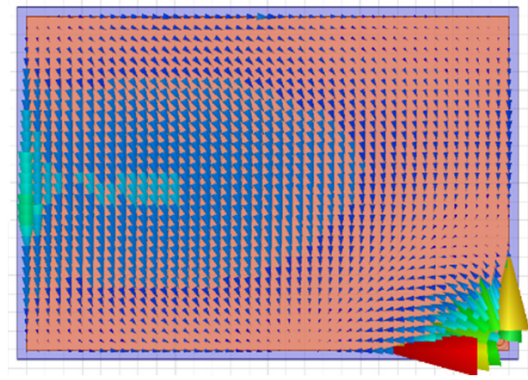

(b)

Figure 8. Surface current distribution without elements upon the patch at (a) $402.5 \mathrm{MHz}$ and at (b) $2.45 \mathrm{GHz}$.

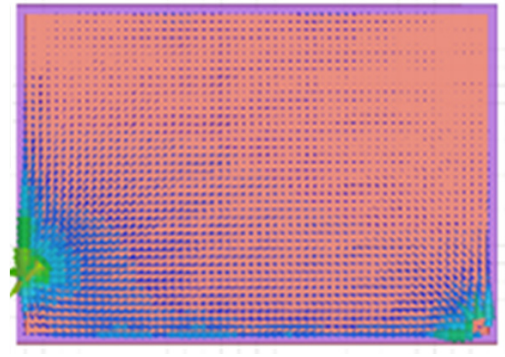

(a)

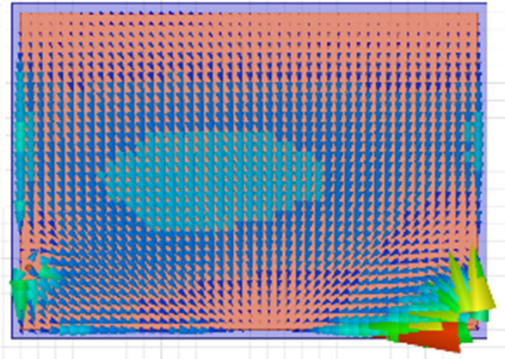

(b)

Figure 9. Impact of the shorting pin on the surface current distribution at (a) $402.5 \mathrm{MHz}$ and at (b) $2.45 \mathrm{GHz}$.

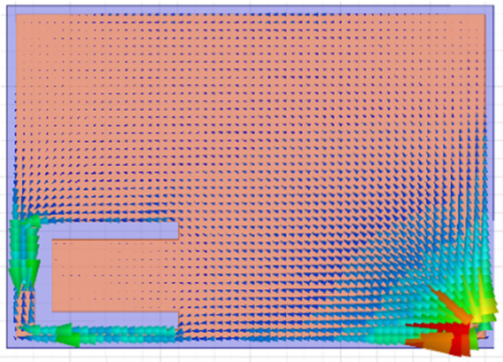

(a)

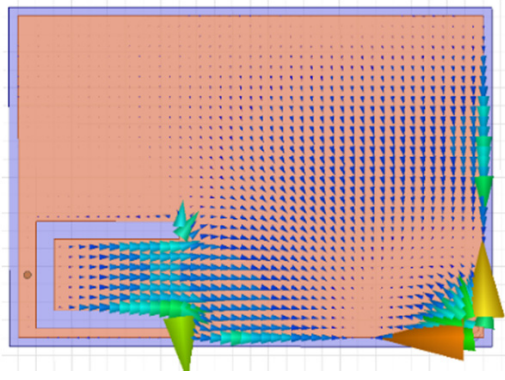

(b)

Figure 10. Surface current distribution with the shorting pin and one of the U-slots at (a) $402.5 \mathrm{MHz}$ and at (b) $2.45 \mathrm{GHz}$.

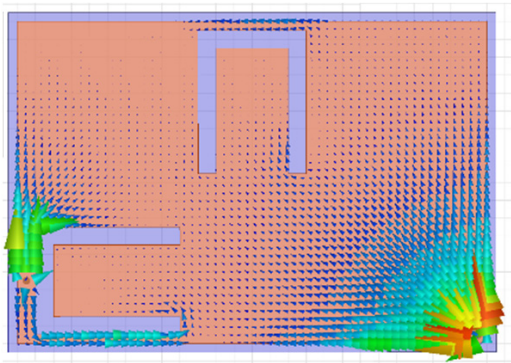

(a)

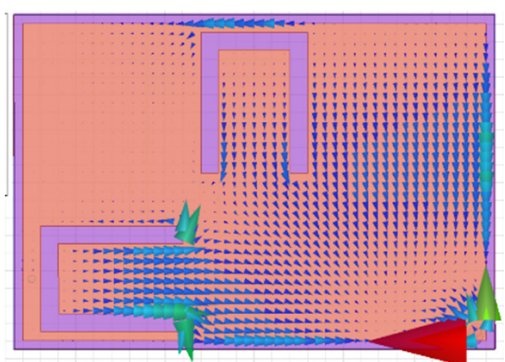

(b)

Figure 11. Surface current distribution of the final antenna design at (a) $402.5 \mathrm{MHz}$ and at (b) $2.45 \mathrm{GHz}$. 
At $402.5 \mathrm{MHz}$, the surface current was mostly concentrated near the feed. Adding the shorting pin, the surface current was directed towards the pin, as shown in Figure 9a. This explains the resonance that occurred with the pin insertion, noted before. Adding the U-shaped slots distributed the surface current around the perimeter of the antenna surface, as shown in Figures 10a and 11a, and shifted the resonance to the left. As a result of these changes, the antenna tuned in the MedRadio band. In the ISM band, the shorting pin did not much affect the surface current's course.

It was observed that the current distribution was concentrated in the middle of the surface, as shown in Figure 9b. Changes occurred in the surface current distribution due to the U-slots, as displayed in Figures $10 \mathrm{~b}$ and $11 \mathrm{~b}$, which made the antenna resonance shift to the left and tune at the ISM band. In the ISM band, the current distribution was more affected by the U-slots than by the pin, compared with the MedRadio band.

\subsubsection{Realized Gain}

It was observed that in every stage of the antenna design the $3 \mathrm{D}$ radiation pattern changed depending on the frequency of interest and the results are displayed in Figures 12-15. Peak radiation concentration is shown in red color.

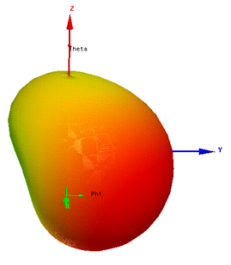

(a)

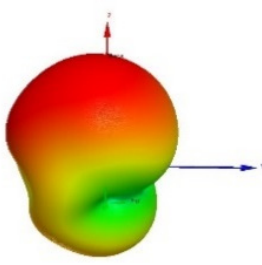

(b)

Figure 12. Realized gain without elements upon the patch at (a) $402.5 \mathrm{MHz}$ and (b) $2.45 \mathrm{GHz}$.

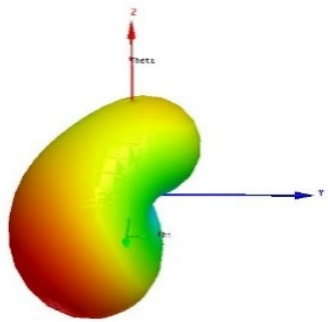

(a)

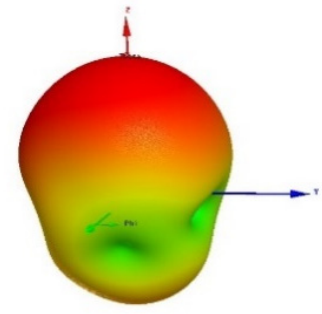

(b)

Figure 13. Realized gain with the shorting pin at (a) $402.5 \mathrm{MHz}$ and (b) $2.45 \mathrm{GHz}$.

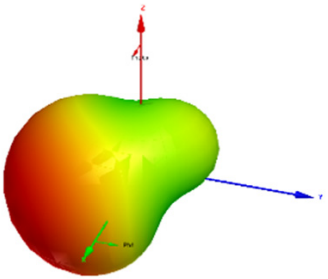

(a)

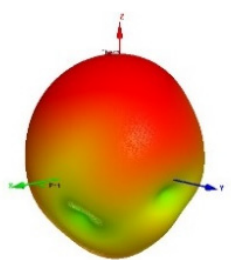

(b)

Figure 14. Realized gain of with the shorting pin and one of the U-slots upon the patch at (a) $402.5 \mathrm{MHz}$ and (b) $2.45 \mathrm{GHz}$. 


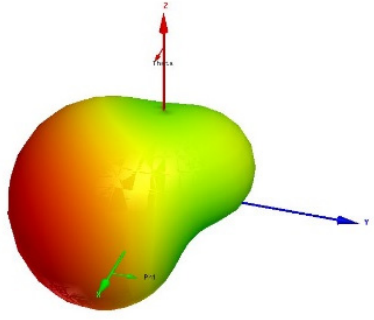

(a)

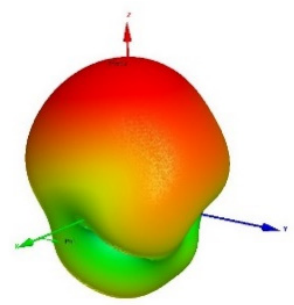

(b)

Figure 15. Realized gain at (a) $402.5 \mathrm{MHz}$ and (b) $2.45 \mathrm{GHz}$.

Moreover, realized gain values changed with the structure modifications and reached their peak values with $-31 \mathrm{~dB}$ at $402.5 \mathrm{MHz}$ and $-22 \mathrm{~dB}$ at $2.45 \mathrm{GHz}$. The antenna showed directional behavior in both frequencies. In the MedRadio band, the radiation pattern was directed to the $x-(-y)$, as shown in Figure 15a plane, and in the ISM band, it was directed to the $\mathrm{z}$ axis. Table 2 shows the results of maximum Realized Antenna Gain extracted from simulations.

Table 2. Results of maximum Realized Antenna Gain extracted from simulations.

\begin{tabular}{ccc}
\hline Frequency & $\begin{array}{c}\text { Realized Gain (dB) } \\
\text { at } 402.5 \mathrm{MHz}\end{array}$ & $\begin{array}{c}\text { Realized Gain (dB) } \\
\text { at 2.45 GHz }\end{array}$ \\
\hline Without Elements & -42.4 & -24.6 \\
Shorting pin & -35 & -22.3 \\
Shorting pin and U-slot & -30.8 & -24.1 \\
Proposed Antenna & -31 & -22 \\
\hline
\end{tabular}

\subsubsection{Electric Current Distribution}

In general, complex phenomena were observed in the electric field due to the small size of the antenna so it was difficult to predict its distribution. However, we can draw some useful conclusions. For $1 \mathrm{~W}$ input power at the feed, the maximum electric field at $402.5 \mathrm{MHz}$ was $3408 \mathrm{~V} / \mathrm{m}$, and at $2.45 \mathrm{GHz}$, it was $3770 \mathrm{~V} / \mathrm{m}$. The peak values of the electric field for both frequencies are shown in the Table 3.

Table 3. Maximum Electric Field and Antenna Structure Modifications extracted from the simulations.

\begin{tabular}{ccc}
\hline $\begin{array}{c}\text { Structure } \\
\text { Modifications }\end{array}$ & $\begin{array}{c}\text { Electric Field }(\mathrm{V} / \mathrm{m}) \\
\text { at } \mathbf{4 0 2 . 5} \mathbf{~ M H z}\end{array}$ & $\begin{array}{c}\text { Electric Field }(\mathrm{V} / \mathrm{m}) \\
\text { at } \mathbf{2 . 4 5} \mathbf{~ G H z}\end{array}$ \\
\hline Without Elements & 47.7 & 2501.6 \\
Shorting pin & 1007.5 & 1885.9 \\
Shorting pin and U-slot & 3554 & 4784.5 \\
Proposed Antenna & 3408.6 & 3770.6 \\
\hline
\end{tabular}

Electric field distribution at $402.5 \mathrm{MHz}$ when every component is inserted is shown in Figure 16. Initially, the electric field of the plane microstrip antenna was very weak, with a maximum value $47 \mathrm{~V} / \mathrm{m}$ and equally distributed in the conductive surface. As we inserted the shorting pin, the electric field concentrated on the edges, and the maximum value changed to $1007 \mathrm{~V} / \mathrm{m}$. This also shows why the resonance occurs when we insert the pin. When the $U$ slots are added, the electric field distribution did not present significant changes, and the maximum values increased to $3408 \mathrm{~V} / \mathrm{m}$ for the proposed antenna, which explained why the tunning improved with these structure modifications. Obviously, we fully exploited the antenna surface to achieve maximum radiation. 


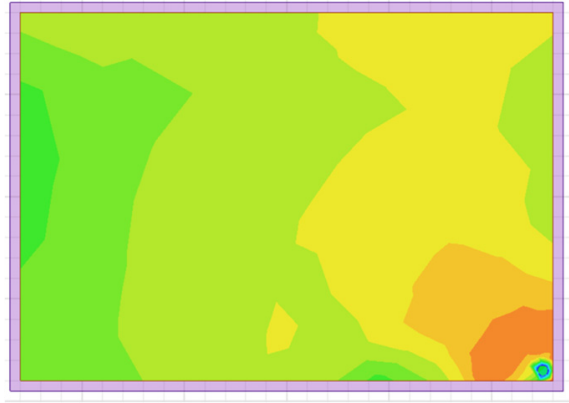

(a)

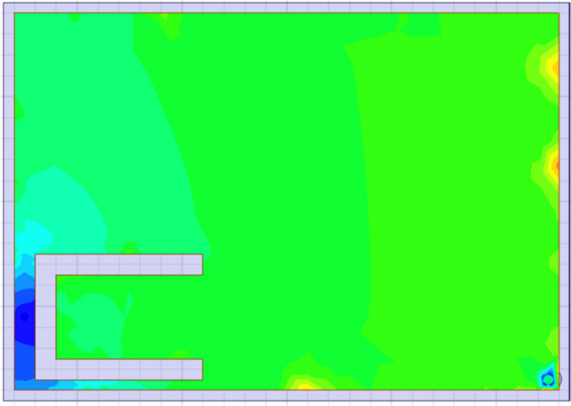

(c)

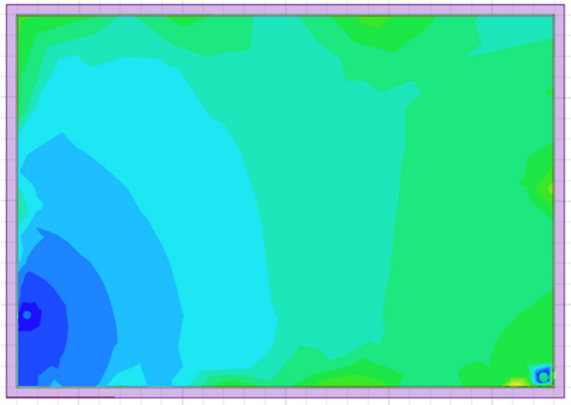

(b)

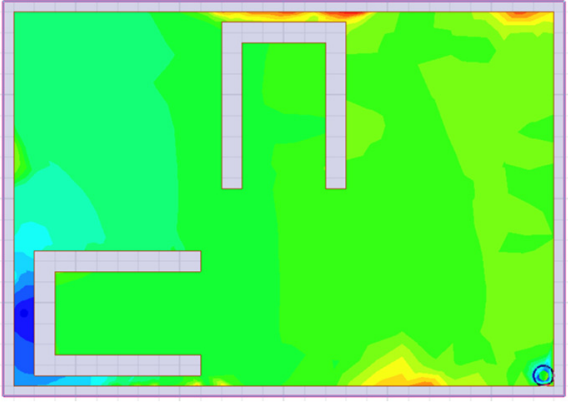

(d)

Figure 16. Electric field distribution of the modified antenna at $402.5 \mathrm{MHz}$ without structure modifications (a), after inserting the sorting pin (b), after inserting the first U-slot (c), and after inserting the second U-slot (d).

Figure 17 shows the electric field distribution of the proposed antenna at $402.5 \mathrm{MHz}$ displayed in two- dimensional and three-dimensional space as displayed from our simulations.

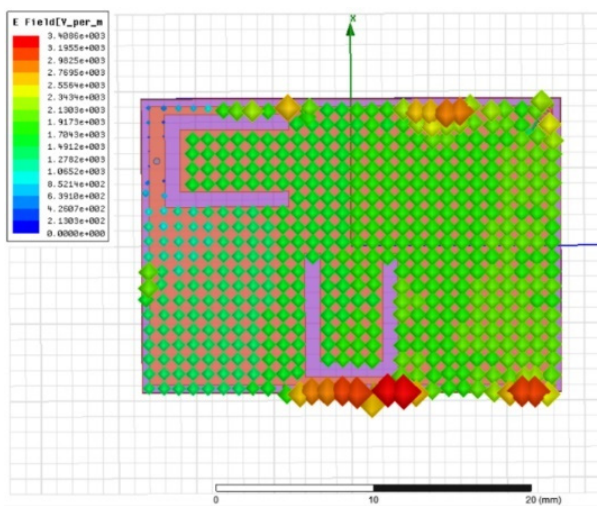

(a)

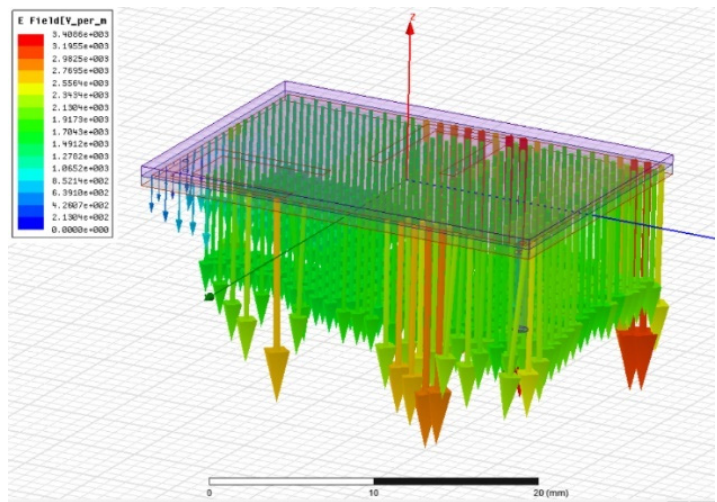

(b)

Figure 17. Electric field distribution of the proposed antenna at $402.5 \mathrm{MHz}$ displayed in two- dimensional (a) and three-dimensional space (b) as displayed from our simulations.

The electric field distribution at the ISM band, displayed in Figure 18, was similar in all steps of the design procedure, as the resonant mode already existed from the plain microstrip patch antenna before inserting any elements. It was observed that the maximum electric field distribution was found on the edges and the maximum value was at $2501 \mathrm{~V} / \mathrm{m}$ before any modification while it increased to $3770 \mathrm{~V} / \mathrm{m}$ after adding all the elements. In this case, antenna radiation mechanisms changed. Less than half of the antenna volume is now used, and resonance is along the $\mathrm{x}$ axis. 


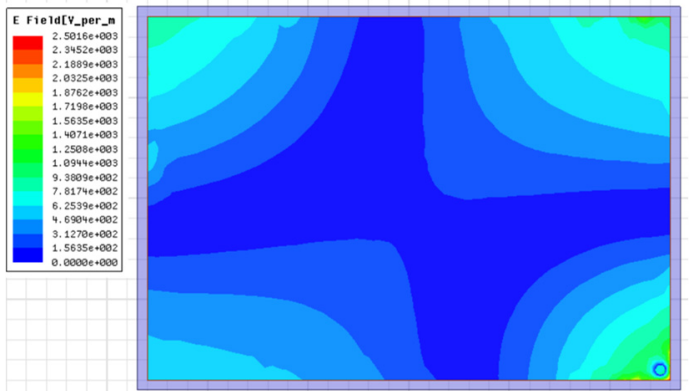

(a)

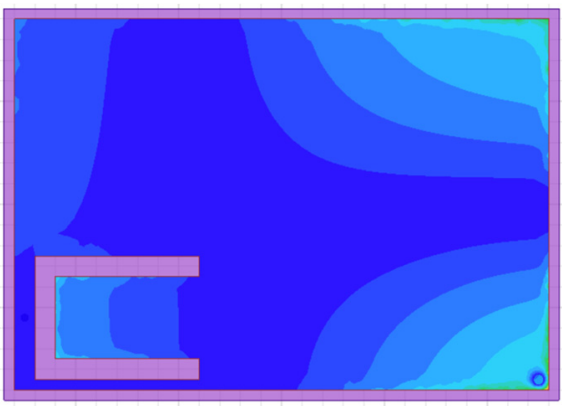

(c)

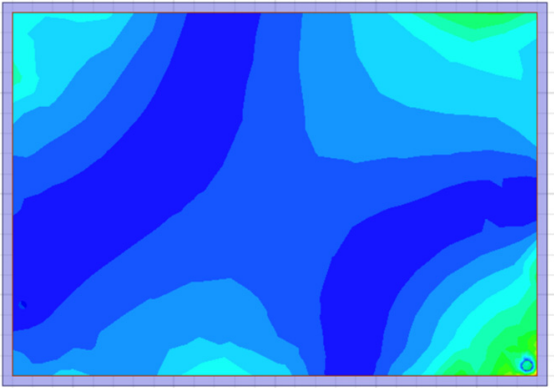

(b)

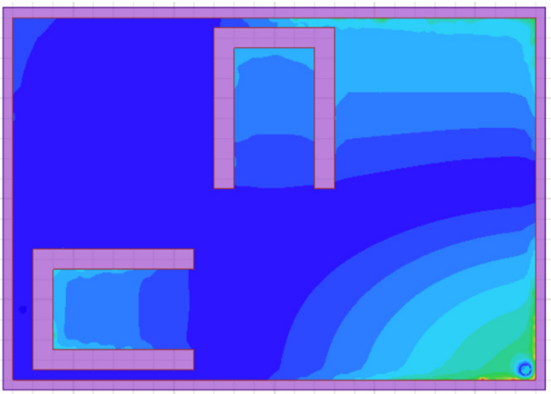

(d)

Figure 18. Electric field distribution of the modified antenna at $2.45 \mathrm{GHz}$ with no structure modifications (a), after inserting the sorting pin (b), after inserting the first U-slot (c), and after inserting the second U-slot (d).

Figure 19 shows the electric field density of the proposed antenna at $2.45 \mathrm{GHz}$ displayed in two- dimensional and three-dimensional space.

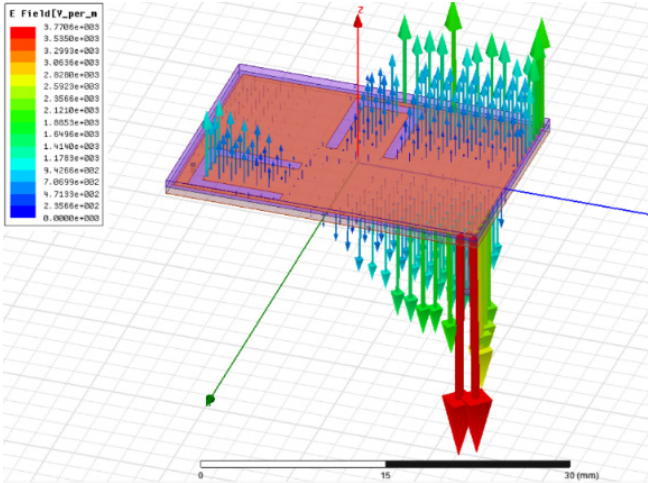

(a)

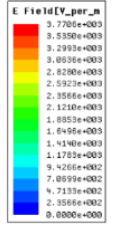

(b)

Figure 19. Electric field density of the proposed antenna at $2.45 \mathrm{GHz}$ displayed in two- dimensional (a) and three-dimensional space (b).

\subsection{Antenna Simulation in Anatomical Models}

Furthermore, we studied the electromagnetic behavior of the proposed antenna when it was placed in an anatomical model that simulated the human body with all the electrical properties at the frequencies of interest and the corresponding tissue dimensions, depending on the age and sex of the anatomical model. The radiation from the antenna inside the human body and the spatial loss index, which determines the safety of the patient, were examined and characterized. The software of the company ZMT Zurich MedTech AG, 
Sim4Life [18] was used for the implementation of the simulation. We selected two typical anatomical models from the models ViP3.1 virtual population, as shown in Figure 20.

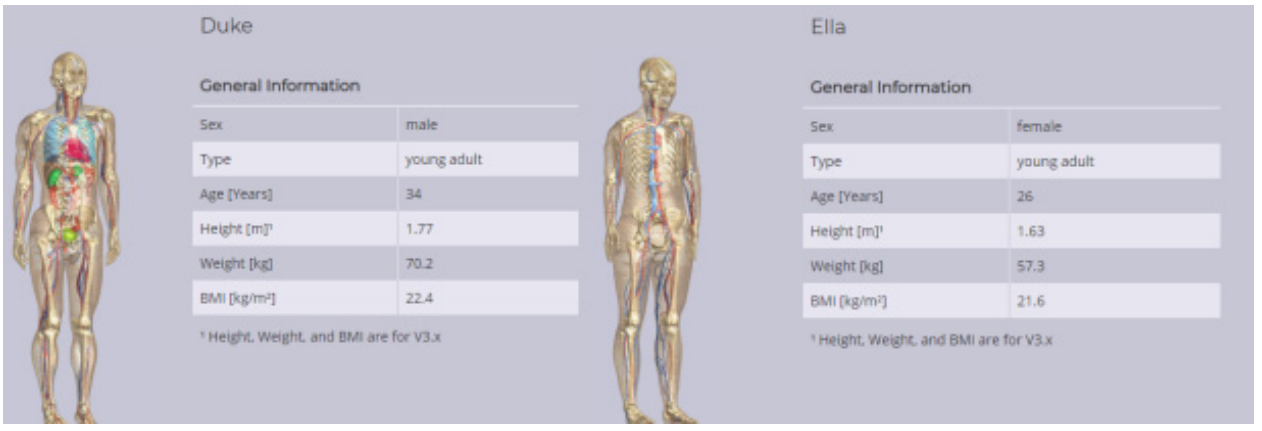

Figure 20. Selected anatomical models from the ViP3.1 virtual population.

The pancreas is located in the terrestrial area, as illustrated in Figure 21; hence, the behavior of the antenna is mainly affected by the surrounding organs and tissues. In the simulation, there were 75 different tissues that were taken into account. Their electrical properties per frequency were obtained from the IT'IS Foundation [18].

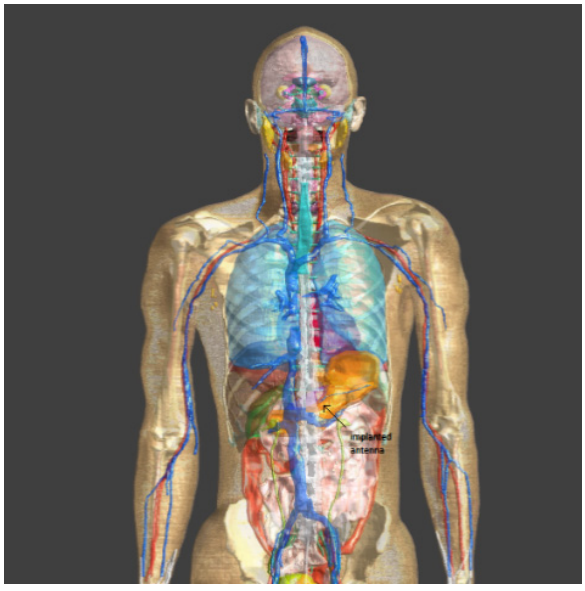

(a)

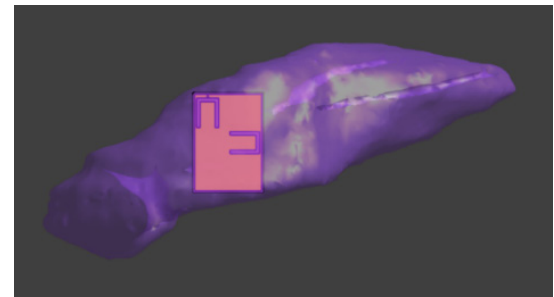

(b)

Figure 21. Anatomical model (a) and simulation of the implanted antenna on the pancreas surface (b).

\subsubsection{Reflection Coefficient}

Male Phantom

After inserting the antenna into the FDTD mesh, S11 was recalculated to verify antenna tuning to the selected frequencies $(402.5 \mathrm{MHz}, 2.45 \mathrm{GHz})$. For the male phantom, as we can see in Figure 22, the implanted antenna's reflection coefficient was $-11.9 \mathrm{~dB}$ at $402.5 \mathrm{MHz}$ and $-11.6 \mathrm{~dB}$ at $2.45 \mathrm{GHz}$. This value was below the $-10 \mathrm{~dB}$ limit. As can be seen, the resonance has moved slightly. Still, because of the impedance bandwidth, $402.5 \mathrm{MHz}$ and $2.45 \mathrm{GHz}$ were satisfactorily covered. It should be noted though that not only changes in the environment but also different modeling techniques can affect the antenna's simulated performance.

\section{Female Phantom}

As we see in Figure 23, the implanted antenna showed at $402.5 \mathrm{MHz}$ a reflection coefficient of $-10.65 \mathrm{~dB}$, while at $2.45 \mathrm{GHz}$ it had a reflection coefficient of $-12.4 \mathrm{~dB}$. These values were below the $-10 \mathrm{~dB}$ limit. They were considered acceptable for the signal transmission power outside the body. 


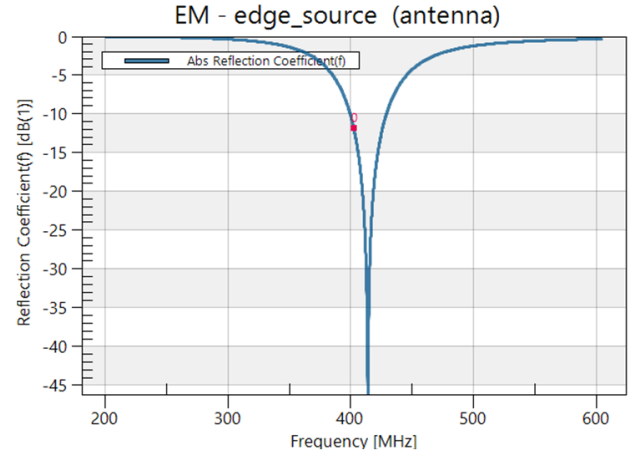

(a)

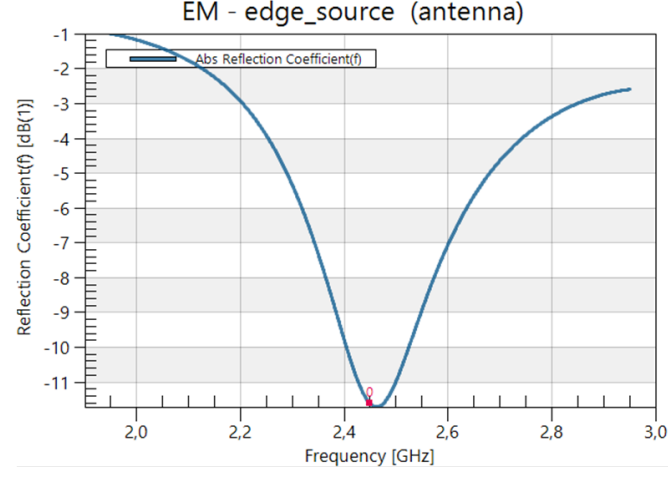

(b)

Figure 22. Resonance performance at (a) $402.5 \mathrm{MHz}$ and (b) $2.45 \mathrm{GHz}$ of the male human phantom.

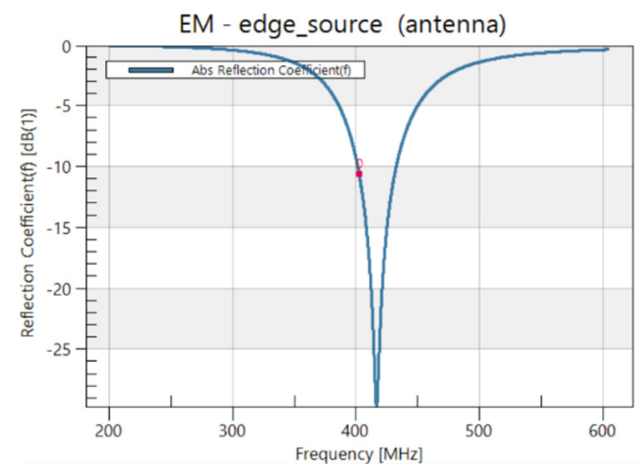

(a)

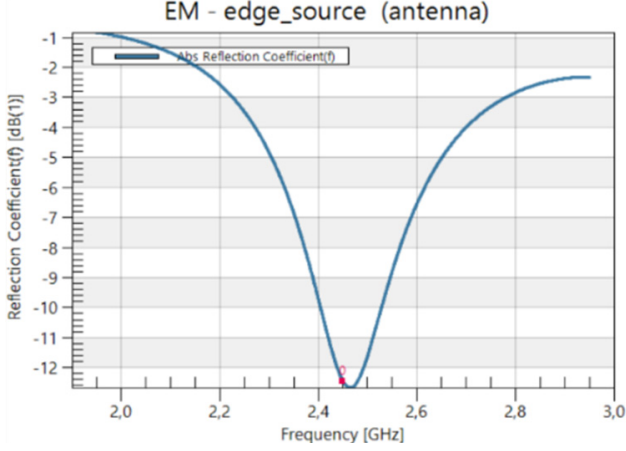

(b)

Figure 23. Resonance performance at (a) $402.5 \mathrm{MHz}$ and (b) $2.45 \mathrm{GHz}$ of the female human phantom.

\subsubsection{Specific Absorption Rate}

The specific absorption rate (SAR) is the most important parameter for quantifying the electromagnetic radiation in human tissues in IEEE C95.1-2019, and [19] specified that the SAR $1 \mathrm{~g}$ and $10 \mathrm{~g}$ averages should not exceed $1.6 \mathrm{~W} / \mathrm{kg}$ and $2 \mathrm{~W} / \mathrm{kg}$, respectively.

We set the input power equal to $1 \mathrm{~W}$. In the male anatomical model, at $402.5 \mathrm{MHz}$ the maximum SAR values for mass $1 \mathrm{~g}$ (pSAR1g) and $10 \mathrm{~g}$ (pSAR10g) were $148.38 \mathrm{~W} / \mathrm{kg}$ and $59.6 \mathrm{~W} / \mathrm{kg}$, respectively. At $2.45 \mathrm{GHz}$ the maximum values of SAR in mass $1 \mathrm{~g}$ (pSAR1g) and $10 \mathrm{~g}$ (pSAR10g) were equal to $217.4 \mathrm{~W} / \mathrm{kg}$ and $57 \mathrm{~W} / \mathrm{kg}$, respectively. In the female anatomical model, at $402.5 \mathrm{MHz}$ the maximum SAR values for mass $1 \mathrm{~g}$ (pSAR1g) and $10 \mathrm{~g}$ (pSAR10g) were $192.34 \mathrm{~W} / \mathrm{kg}$ and $63.48 \mathrm{~W} / \mathrm{kg}$. At $2.45 \mathrm{GHz}$ the maximum values of SAR in mass $1 \mathrm{~g}$ (pSAR1g) and $10 \mathrm{~g}$ (pSAR10g) were equal to $258.5 \mathrm{~W} / \mathrm{kg}$ and $61.62 \mathrm{~W} / \mathrm{kg}$, respectively.

As we can observe, the values of SAR were high, compared against the specified limits. This was expected for $1 \mathrm{~W}$ input power. However, for implanted sensors, antennas are expected to operate at much lower power, usually not exceeding $0 \mathrm{~mW}$. As shown in the summary Table 4, the antenna was safe to use, with a maximum permissible input power (Pmax) much higher than $1 \mathrm{~mW}$.

Table 4. Specific absorption rate and maximum permissible input power.

\begin{tabular}{cccccc}
\hline $\begin{array}{c}\text { Human } \\
\text { Phantom }\end{array}$ & Frequency & $\begin{array}{c}\text { SAR, 1 g } \\
\text { (W/kg) }\end{array}$ & $\begin{array}{c}\text { Pmax, 1 g } \\
\text { (mW) }\end{array}$ & $\begin{array}{c}\text { SAR, 10 g } \\
\text { (W/kg) }\end{array}$ & $\begin{array}{c}\text { Pmax, 10 g } \\
\text { (mW) }\end{array}$ \\
\hline \multirow{2}{*}{ Male } & $402.5 \mathrm{MHz}$ & 148.38 & 10.8 & 59.6 & 33.6 \\
& $2.45 \mathrm{GHz}$ & 217.4 & 7.4 & 57 & 35.1 \\
\hline \multirow{2}{*}{ Female } & $402.5 \mathrm{MHz}$ & 192.34 & 8.3 & 63.48 & 31.5 \\
& $2.45 \mathrm{GHz}$ & 258.5 & 6.1 & 61.62 & 32.4 \\
\hline
\end{tabular}


Figure 24 shows the spatial distribution of SAR for $10 \mathrm{~g}$ tissue mass at $402.5 \mathrm{MHz}$ in the male anatomical model front side and left side extracted from Sim4Life simulation software [16].

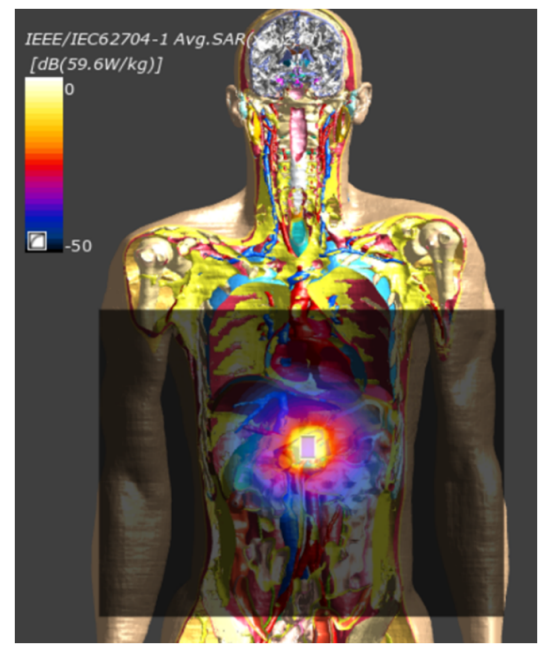

(a)

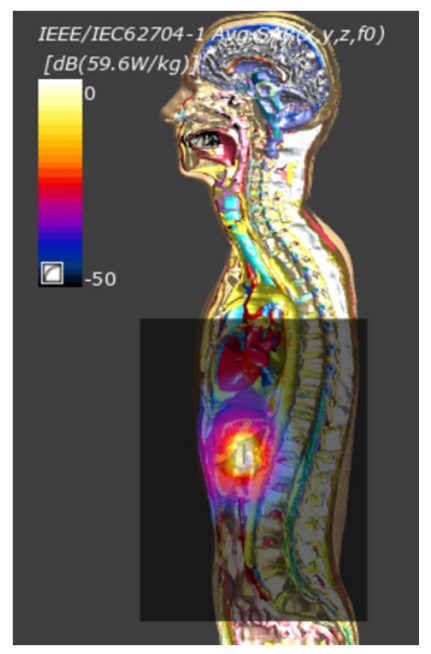

(b)

Figure 24. Spatial distribution of SAR for $10 \mathrm{~g}$ tissue mass at $402.5 \mathrm{MHz}$ in the male anatomical model (a) front side (b) left side extracted from Sim4Life simulation software [16].

\subsubsection{Electrical Field Attenuation}

The attenuation of the normalized electric field when the electromagnetic wave propagated from the pancreas to the external space of anatomical model in both directions of $x$ axis as a function of distance and when the antenna operated at $402.5 \mathrm{MHz}$ and $2.45 \mathrm{GHz}$ is shown in Figures 25 and 26. As noted, when the electric field propagated outside the body, attenuation followed well known curves [20].

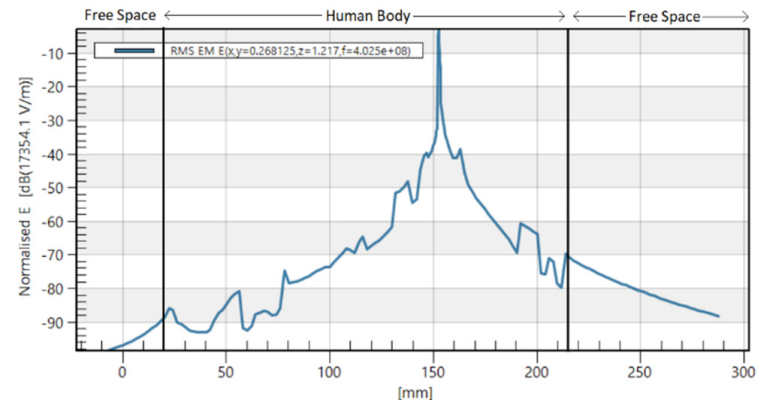

(a)

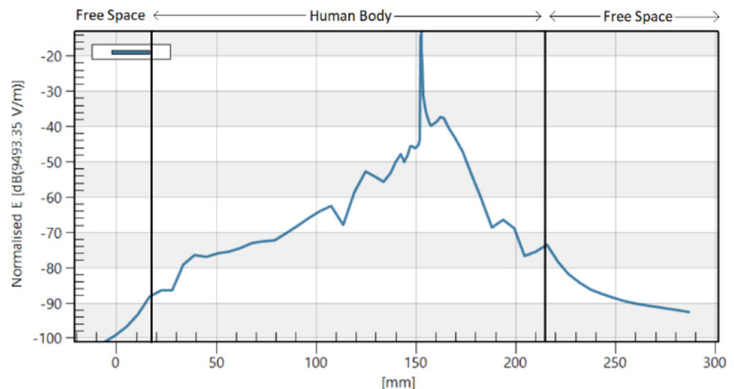

(b)

Figure 25. Attenuation of electric field along the x-cut of the male human phantom at (a) $402.5 \mathrm{MHz}$ and (b) $2.45 \mathrm{GHz}$. 


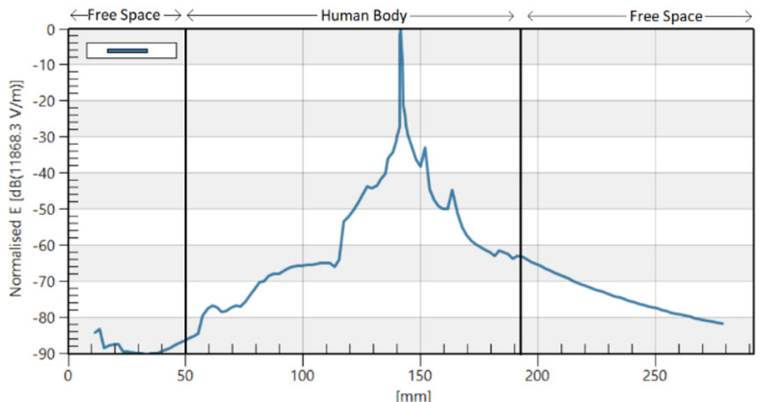

(a)

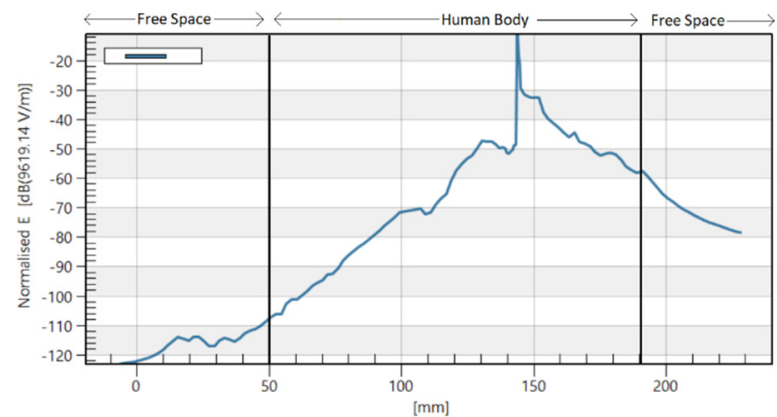

(b)

Figure 26. Attenuation of electric field along the x-cut of the female human phantom at (a) $402.5 \mathrm{MHz}$ and (b) $2.45 \mathrm{GHz}$.

\subsubsection{Total Radiated Power (TRP)}

The value of total radiated power (TRP) in the male anatomical model was estimated to be $-15 \mathrm{dBm}$ at $402.5 \mathrm{MHz}$ and $-16 \mathrm{dBm}$ at $2.45 \mathrm{GHz}$. In the female anatomical model TRP was calculated $-9 \mathrm{dBm}$ at $402.5 \mathrm{MHz}$ and $-14 \mathrm{dBm}$ at $2.45 \mathrm{GHz}$ when the input power was $1 \mathrm{~W}$.

It was observed that the gain and the total radiated power (TRP) were somewhat higher in the female model. This may be due to the anatomical differences between the male and female body. In the male body, the pancreas is covered by the stomach and liver. In contrast, in the female body, the pancreas is covered only by the small intestine. Thus, the radiated power has fewer obstacles as it is propagated to the external receiver.

\section{Discussion}

In this paper, an implantable dual-band antenna for biomedical telemetry was designed to operate at MedRadio and ISM bands. Miniaturization and dual-band function were attained by adding a shorting pin and cutting U-shaped slots on the patch surface. The performance of the proposed antenna was evaluated inside a pancreas equivalent model, and the resonance and radiation performance were found to be within acceptable limits for an implantable device.

In addition, for a more accurate estimation of the implantable antenna behavior, the antenna was simulated and measured in the pancreas' surface of a male and a female human phantom. As seen from the analysis of the simulation results, resonance, radiation, and patient safety performance were considered satisfactory for the desired frequencies in both human phantoms. The reflection coefficient in both cases satisfied the $-10 \mathrm{~dB}$ limit. Nonetheless, at $402.5 \mathrm{MHz}$, there was a shift in the S11 resonance as compared with the cubic model. Finally, gain and radiated power were low due the antenna's small size and the absorption of radiation by the tissues surrounding the pancreas, with slightly better values in the female human phantom. 
The possibilities that implantable devices can offer to medicine and human body networks in general offer a variety of research perspectives. Future extensions of this work for further investigation of the wireless channel within the human body could be the following:

- Application of the proposed antenna to the other anatomical models provided by Sim4Life to study its performance and compare results.

- Extension of the wireless antenna connection study, within an anatomical model with an external receiver, inside a medical room.

- Further downsizing of the proposed antenna designed in this work, with structure modifications and algorithms.

- The construction of the proposed antenna could be carried out to study in vitro its behavior in a real environment within a liquid or gel that simulates the dielectric characteristics of human tissue. Such methods have been used in Reference [3] for exporting experimental data.

Author Contributions: Writing—original draft preparation, M.M.; writing—review and editing, S.K. (Stavros Koulouridis); supervision, S.K. (Stavros Kotsopoulos). All authors have read and agreed to the published version of the manuscript.

Funding: This research received no external funding.

Data Availability Statement: This article is an extended version of our paper [5] presented in MOCAST Conference.

Conflicts of Interest: The authors declare no conflict of interest.

\section{References}

1. Kiourti, A.; Nikita, K.S. A review of in-body biotelemetry devices: Implantables, ingestibles, and injectables. IEEE Trans. Biomed. Eng. 2017, 64, 1422-1430. [CrossRef] [PubMed]

2. Lee, C.-M.; Yo, T.-C.; Huang, F.-J.; Luo, C.-H. Dual-resonant П-shape with double L-strips PIFA for implantable biotelemetry. Electron. Lett. 2008, 44, 837-838. [CrossRef]

3. Karacolak, T.; Hood, A.Z.; Topsakal, E. Design of a dual-band implantable antenna and development of skin mimicking gels for continuous glucose monitoring. IEEE Trans. Microw. Theory Tech. 2008, 56, 1001-1008. [CrossRef]

4. Bakogianni, S.; Koulouridis, S. A Dual-Band Implantable Rectenna for Wireless Data and Power Support at Sub-GHz Region. IEEE Trans. Antennas Propag. 2019, 67, 6800-6810. [CrossRef]

5. Matthaiou, M.; Koulouridis, S.; Kotsopoulos, S. Design and Analysis of an Implantable Dual-Band Antenna for Pancreas Biotelemetry. In Proceedings of the 2021 10th International Conference on Modern Circuits and Systems Technologies (MOCAST), Thessaloniki, Greece, 5-7 July 2021.

6. Bonefačić, D.; Rapinac, B. Some considerations on size reduction of a microstrip patch antenna. In Proceedings of the 2007 19th International Conference on Applied Electromagnetics and Communications, Dubrovnik, Croatia, 24-26 September 2007; pp. 3-6. [CrossRef]

7. Kumar, P.; Singh, G. Microstrip Antennas Loaded with Shorting Post. Engineering 2009, 1, 41-45. [CrossRef]

8. Moghariya, D.; Kothari, T.; Patel, P.M.P. Miniaturisation Method to Reduce the Size of Microstrip Antenna for Lower Frequency. Int. J. Sci. Res. Dev. 2013, 1, 26-28.

9. Kiourti, A.; Tsakalakis, M.; Nikita, K.S. Parametric study and design of implantable PIFAs for wireless biotelemetry. Lect. Notes Inst. Comput. Sci. Soc. Telecommun. Eng. 2012, 83, 96-102. [CrossRef]

10. Kim, J.; Rahmat-Samii, Y. Implanted antennas inside a human body: Simulations, designs, and characterizations. IEEE Trans. Microw. Theory Tech. 2004, 52, 1934-1943. [CrossRef]

11. Clenet, M.; Shafai, L. Multiple resonances and polarisation of U-slot patch antenna. Electron. Lett. 1999, 35, 101-103. [CrossRef]

12. Ghalibafan, J.; Attari, A.; Kashani, F. A New Dual-Band Microstrip Antenna with U-Shaped Slot. Prog. Electromagn. Res. C 2010, 12, 215-223. [CrossRef]

13. Thakur, V.; Kashyap, S. Implementation and Developments of Single Feed Design using Multiple U- Slotted Patch Antenna for Wireless Applications. Int. J. Eng. Res. 2015, 4, 93-98. [CrossRef]

14. Lee, K.-F.; Yang, S.L.S.; Kishk, A.A. Dual- and multiband U-slot patch antennas. IEEE Antennas Wirel. Propag. Lett. 2008, 7, 645-647. [CrossRef]

15. Ansys Electronics Suite18.2; Ansys Inc.: Canonsburg, PA, USA, 2018.

16. Sim4Life, Ver. 5.2.1.1375, ZMT Zurich MedTech AG, Zeughausstrasse 43, Zurich, Switzerland. Available online: https://zmt. swiss/sim4life/ (accessed on 1 October 2020).

17. Huynh, T.; Lee, K.-F. Single-layer single-patch wideband microstrip antenna. Electron. Lett. 1995, 31, 1310-1312. [CrossRef] 
18. Hasgall, P.A.; Di Gennaro, F.; Baumgartner, C.; Neufeld, E.; Lloyd, B.; Gosselin, M.C.; Payne, D.; Klingenböck, A.; Kuster, N. IT'IS Database for Thermal and Electromagnetic Parameters of Biological Tissues. Version 4.0, 15 May 2018. Available online: https:/ / itis.swiss/virtual-population/tissue-properties/downloads/database-v4-0/ (accessed on 1 October 2020).

19. IEEE Standard for Safety Levels with Respect to Human Exposure to Electric, Magnetic, and Electromagnetic Fields, $0 \mathrm{~Hz}$ to 300 GHz. In IEEE Std C95.1-2019 (Revision of IEEE Std C95.1-2005/Incorporates IEEE Std C95.1-2019/Cor 1-2019); IEEE: New York, NY, USA, 2019; pp. 1-312. [CrossRef]

20. Alomainy, A.; Hao, Y.; Yuan, Y.; Liu, Y. Modelling and Characterisation of Radio Propagation from Wireless Implants at Different Frequencies. In Proceedings of the 2006 European Conference on Wireless Technology, Manchester, UK, 10-12 September 2006; pp. 119-122. [CrossRef] 